\title{
Uma proposta para o Ensino de Física por meio de problematizações
}

\section{A proposal for teaching physics through problematizations}

\author{
Samira Cassote Grandi França (samyracassote@gmail.com) \\ Doutoranda pelo Programa de Pós-Graduação em Educação para a Ciência e a Matemática. Universidade \\ Estadual de Maringá \\ Luciano Carvalhais Gomes (lcgomes2@uem.br) \\ Doutor em Educação para a Ciência e a Matemática. Universidade Estadual de Maringá \\ Marcelo Christiano da França Júnior (marcelo.franca@ifms.edu.br) \\ Mestre em Engenharia Elétrica. Instituto Federal de Mato Grosso do Sul
}

\begin{abstract}
Resumo: Este trabalho apresenta os resultados de um estudo cujo objetivo foi identificar e analisar as estatégias utilizadas por professores de Física sobre os conceitos da Termodinâmica presente em periódicos e eventos nacionais do Ensino de Física, além de apresentar estratégias que venha tornar este ensino mais significativo ao aluno. Os dados foram construídos primeiramente por uma seleção dos periódicos por meio do portal de periódicos da CAPES que apresentassem qualis A1 e A2 no novo qualis, e posteriormente realizou-se um levantamento de trabalhos publicados e apresentados em eventos no período de 2010 a 2020. Os trabalhos foram analisados com base na Análise de Conteúdo. Entre os conceitos mais estudados está o de calor, temperatura e processos de transferência, e as estratégias vão desde experimentos, simulações, problematizações, textos e questionários. Os resultados apontam para a necessidade da exploração dos significados e diferenciação dos conceitos de calor e temperatura, por se tratar dos conceitos base da Termodinâmica e apesar da eficiência de algumas abordagens, destaca-se a necessidade da clareza dos objetivos e focos pretendidos com o recurso utilizado e os delineamentos após sua utilização para que estes não recaiam em apenas ludicidade.
\end{abstract}

Palavras-chave: Levantamento bibliográfico; Termodinâmica; Ensino de Física.

Abstract: This work presents the results of a study whose objective was to identify and analyze the strategies used by physics teachers on the concepts of thermodynamics present in national physics teaching journals and events, in addition to presenting strategies that will make this teaching more meaningful to the student. The data were first constructed by a selection of journals through the CAPES journals portal that presented qualifications $\mathrm{A} 1$ and $\mathrm{A} 2$ in the new qualis, and subsequently a survey of works published and presented in events from 2010 to 2020 was carried out. works were analyzed based on Content Analysis. Among the most studied concepts is that of heat, temperature and transfer processes, and the strategies range from experiments, simulations, problematizations, texts and questionnaires. The results point to the need to explore the meanings and differentiate the concepts of heat and temperature, as they are the basic concepts of Thermodynamics and despite the efficiency of some approaches,

Recebido em: 18/01/2021

Aceito em: 24/02/2021 
the need for clarity of the objectives and focuses intended with the resource is highlighted. used and the outlines after its use so that they do not fall into just playfulness.

Keywords: Bibliographic survey; Thermodynamics; Physics Teaching

\section{INTRODUÇÃO}

Nos últimos anos o ambiente escolar vem passando por profundas mudanças, sendo desafiado a se transformar de um ambiente de mera transmissão de conteúdos para um local onde se estimule a criação de habilidades e competências, visando a autonomia e o pensamento crítico, além dos conhecimentos essenciais para o desenvolvimento pessoal e social.

Neste cenário, o ensino de Física deve instruir o aluno para além do âmbito escolar, permitindo que este desenvolva na escola, “[...] habilidades que the permita atuar consciente e racionalmente fora do contexto escolar, estabelecendo julgamentos e opiniões sobre assuntos variados que afetam sua vida" (CARVALHO, 2011, p. 107), sendo capazes ainda de "[...] questionar a realidade, de resolver problemas utilizando para isso o pensamento lógico, a criatividade, a intuição, a capacidade de análise crítica, selecionando procedimentos e verificando sua adequação" (BEZERRA, et al 2009, p.2).

No entanto, nos últimos anos avaliações de cunho internacional como o Programa Internacional de Avaliação de Estudantes (PISA) e nacional como o Exame Nacional do Ensino Médio (ENEM) vêm indicando de forma objetiva o despreparo dos estudantes em relação à aprendizagem, entre eles destaca-se a dificuldade de aplicar o conhecimento em situações que representam problemas do cotidiano, além do fraco desempenho quando são solicitados a interpretar, explicitar seu aprendizado e a manifestar soluções, como é o caso das questões contextualizadas no ENEM.

A edição mais recente do PISA aplicada em 2018 em 597 escolas Brasileiras pontuou que $68,1 \%$ dos estudantes apresentam desempenho abaixo do nível em matemática, chegando a 55\% em ciências e 50\% em leitura, o que leva a ocupar as últimas posições no ranking. Essa defasagem representa um considerável atraso em relação aos países subdesenvolvidos, o que indica a necessidade em se trabalhar habilidades essenciais ao desenvolvimento pleno do educando (INEP, 2019). 
Edição Especial: I SSAPEC - Simpósio Sul-Americano de Pesquisa em Ensino de Ciências ISSN: 2595- $4520 \quad$ Vol. 4, n. 3. 2021

Segundo Gil Pérez, Martinez Torregrosa e Senent (1988) a maior parte dos professores atrelam este baixo desenvolvimento a falta de conhecimentos teóricos, seja em relação aos temas, conceitos, e leis presentes nos problemas, como também o escasso domínio da linguagem matemática necessária para resolvê-los.

Os estudantes do ensino médio apontam essa dificuldade devido à predominante incidência da matemática presente através das equações, o que leva muitas vezes a simples memorização, sem uma compreensão de seu significado e utilização, também apresentam as vastas listas de exercícios as quais requerem a utilização de várias fórmulas, onde raras às vezes conseguem interpretar qual equação utilizar, além de que reforçam a reprodução sem nenhuma relação com o cotidiano. Também falam sobre a linguagem utilizada pelo professor, os sinais, símbolos e palavras, que causam confusão devido sua complexidade (MENEGOTTO; ROCHA FILHO, 2008).

A este olhar Moreira (2017, p.3) caracteriza o ensino de Física como “[...] desatualizado em termos de conteúdos e tecnologias, centrado no docente, comportamentalista, focado no treinamento para as provas [...] uma ciência acabada, tal como apresentada em um livro de texto", “[...] um conhecimento parcial e descartável, usado somente pra passar no vestibular" (ANTONOWISKI; ALENCAR; ROCHA, 2017, p.51), ao qual pode ser verificado através das incansáveis listas de exercícios, ou resolução de problemas, que por vezes remetem a simples aplicações algébricas de equações, assim, é comum ver "[...] os alunos conseguirem resolver problemas similares aos anteriores, mas fracassarem ou desistirem frente a novas situações" (CLEMENT; TERRAZZAN, 2012, p.100).

Neste cenário, constata-se que apesar do Ensino de Física ser relativamente uma atividade antiga, este ensino como uma área de pesquisa em educação ainda é muito recente, tendo apresentado resultados de práticas e reflexões ainda muito distantes dos ambientes educacionais, além disso, os métodos educacionais são pouco discutidos e estudados por quem de fato está nas salas de aula, o que reforça o insucesso e a dificuldade desta área.

Neste sentido, “é preciso repensar não somente as práticas educacionais, mas também ter cuidado para não pensarmos em nossos alunos como cientistas-mirins, tampouco objetivarmos tão somente a formação de cientistas para o futuro" (CARVALHO; SASSERON, 2018, p.46). A estes aspectos, algumas perguntas acabam 
Edição Especial: I SSAPEC - Simpósio Sul-Americano de Pesquisa em Ensino de Ciências

ISSN: 2595- $4520 \quad$ Vol. 4, n. 3. 2021

por se tornar frequentes entre os educadores: Como deve ser o ensino de física em pleno século XXI? Qual corrente pedagógica seguir? Qual o melhor método de ensino?

Responder a estas questões pode ser uma tarefa difícil e até impossível, haja visto que cada ambiente escolar possui sua realidade, e que cada aluno em sua singularidade tem uma forma diferente de aprender o mesmo conteúdo, neste sentido antes de pensar em um melhor método ou forma de ensinar é preciso refletir que tipo de cidadão queremos formar, e quais habilidades e competências devem priorizar.

A este sentido, os Parâmetros Curriculares Nacionais (PCN) apontam ideias de quais aspectos e objetivos o ensino de física deve se guiar, partindo da necessidade de se “construir uma visão da Física [...] voltada para a formação de um cidadão contemporâneo, atuante e solidário, com instrumentos para compreender, intervir e participar na realidade" (BRASIL, 2002 p.1 ), de modo que ao concluir o ensino médio este tenha adquirido as competências necessárias para compreender e participar do mundo em que vive.

É preciso portanto como professor, reconhecer que o conhecimento físico acumulado ao longo da história precisa passar por um processo de organização e seleção acerca do que deve vir a ser mais importante ou fundamental para o aluno, admitindo sua realidade e regionalidade, além de estar atento as condições específicas do perfil escolar e do projeto pedagógico, assim em vez de refletir "o quê ensinar de Física", possa centrar-se em "para que ensinar Física” (BRASIL, 2002).

Ao pensar nestes aspectos somos levados a reavaliarmos primeiramente alguns princípios, como: O que nossos estudantes precisam compreender da ciência (ler e interpretar gráfico, compreender e utilizar simbolos, compreender conceitos e leis), quais aspectos sociais e emocionais são necessários para o desenvolvimento pessoalcientífico (criticidade, empatia, justiça, entre outros.), e qual linguagem melhor se adequa ao estudo em pauta (textual, falada, gráfica, audiovisual, entre outros.).

Essa mudança de pensamento proporciona um melhor preparo do estudante, de modo que este passa a ser capaz de refletir, questionar/duvidar, levantar hipoteses, compartilhar e aceitar ideias, ser crítico, buscar soluções, trabalhar em conjunto, compreender e lidar com situações reais de seu cotidiano (BRASIL, 2002), propiciando espaços para o trabalho de atividades contextualizadas, interdiciplinares e reais de seu contexto. 
Neste processo a linguagem específica da física também merece destaque, pois de acordo com Vigotski o conhecimento é transferido basicamente por meio da linguagem, e é através dela que se origina o pensamento. Como linguagem da física compreendemos a conceitual, a simbolíca e a matemática. Sendo assim, consideramos importante que no processo de ensino-aprendizagem as três linguagens se articulem de modo que uma não se sobressaia entre as demais, de modo a não propiciar a transmissão de conteúdos e a reprodução de ideias.

A partir das reflexões apresentadas buscamos responder as seguintes questões: Quais são as estratégias metodológicas utilizadas por professores de Física no estudo dos conceitos da Termodinâmica a nível médio presente em periódicos e eventos nacionais de Física?e de que forma os conteúdos podem ser articulados, para que a linguagem matemática não seja o principal recurso/meio para a compreensão dos fenômenos, de modo que os alunos possam se apropriar da linguagem e do conhecimento científico?

Para respondê-las partimos inicialmente de um levantamento bibliográfico em importantes periódicos e eventos nacionais sobre Ensino de Física, a fim de identificar quais as metodologias e recursos são utilizados pelos professores para o ensino e aprendizagem da Termodinâmica a nível médio, e analisá-los em seu contexto. A partir da análise dos trabalhos, buscamos sintetizar as informações apresentando discussões e sugestões sobre possíveis delineamentos para um ensino de física térmica mais dinâmico, participativo e potencializador para o aluno.

A escolha da investigação dos conceitos Termodinâmicos se justifica devido a complexidade que os conceitos representam no meio físico, como por exemplo a definição de energia, a diferenciação entre calor e temperatura, e a influência das experiências cotidianas para a definição do conceito de calor, correspondendo a um dos conceitos mais difíceis de se ensinar e tido pelos alunos como de difícil compreensão devido a dificuldade de abandonar as ideias como "hoje está calor", "feche a porta para o frio não entrar", entre outras. Anida, de acordo com professores que analisam as questões do ENEM, os conceitos que envolvem esta área estão corriqueiramente presente nos exercícios por meio de questões contextualizadas e conceituais, o que mais uma vez justifica nosso interesse pelo estudo da área.

\section{CONSIDERAÇÕES SOBRE O ENSINO DE FÍSICA}




\subsection{Aspectos Teóricos}

Ao estudarmos o processo de ensino e aprendizagem no contexto escolar deve-se levar em consideração dois papéis de extrema importância, o professor como responsável pelo planejamento e mediação do conhecimento, e o aluno como agente ativo no processo de construção do conhecimento, deste modo, vários aspectos vão sendo requisitados, seja por parte do professor como do aluno.

O primeiro ponto de destaque em relação ao papel do professor no ensino começa com o planejamento didático, neste para que aconteça a participação do aluno, sua reflexão, compreensão, e aquisição do conhecimento é necessário primeiramente que o professor tenha clareza da insuficiência do ensino tradicional, deixando de lado manuais e práticas ultrapassadas, para que não recaia na mera transmissão de conhecimentos, deste modo, o professor deve estar ciente de que:

[...] não se aprende a aprender apenas ouvindo, escrevendo, memorizando e reproduzindo conhecimentos em provas, é preciso algo mais dinâmico, que ative os alunos, não apenas fisicamente, mas acima de tudo, intelectualmente. É necessário que ele, o aprendiz, ponha em funcionamento toda a sua estrutura cognitiva durante $\mathrm{o}$ ato de aprender, e consiga ir além dela, refletindo e retomando cada ação efetivada em busca do conhecimento (ROSA; ROSA, 2012, p. 12).

Para isso é preciso que durante o planejamento didático o professor busque formações que visem complementar e proporcionar novas reflexões acerca de como se ensina e aprende em física, uma sugestão é a busca por resultados de pesquisas que apresente aplicações de propostas didáticas, uso de metodologias ativas e a leitura de reflexões teóricas e metodológicas. Ainda para que a aprendizagem de física seja significativa e que de fato haja interesse pelo aluno em compreender a ciência é preciso que o ensino seja atraente e motivador para o aluno, pois a ênfase demasiada em lista de exercícios, e a insistência quase que geral da matemática tem causado aversão, desmotivação e ainda ser a causa do fraco desempenho dos alunos.

Nesta vertente é preciso que o professor esteja ciente que o "conteúdo a ser ensinado deve passar necessariamente por um processo de transformação para se chegar a sala de aula, o que implica em simplificações, ajustes, omissões etc.” (MARTINS, 2015, p.706), além de escolhas metodológicas e assuntos relevantes. 
Bonadiman e Nonenmacher (2007) apresentam uma dinâmica que pode ser utilizada e operacionalizada para cada conteúdo de física, no qual o professor deve preocupar-se em um primeiro momento em:

- Proporcionar ao aluno uma visão geral e contextualizada do tema em estudo;

- Mostrar a importância do tema que está sendo tratado e motivar o aluno para o estudo;

- Possibilitar a fala do aluno sobre questões e situações de sua vivência relacionadas com o tema em estudo; (BONADIMAN; NONENMACHER, 2007, p.206-207)

Para isso, cabe ao professor além de escolhas metodológicas inteligentes, apresentar de forma clara o tema ou assunto a ser estudado, suas conexões e contextualizações com o cotidiano do aluno, ressaltando ainda sua importância e aplicação.

Num segundo momento cabe ao professor por meio das metodologias escolhidas apresentar o conteúdo a ser estudado, para isso o professor deve fomentar o diálogo e a interação professor-aluno, e aluno-aluno, levando os alunos a darem suas opiniões, fomentando a argumentação "sobre os fenômenos, sobre as interpretações dos "fatos científicos", pois é necessário apresentar um ponto de vista com justificativas para transformar fatos e dados em evidências"(CARVALHO; SASSERON, 2018, p.47).

\subsection{Aspectos Metodológicos e de Estratégias para o ensino}

Sobre as metodologias utilizadas nos últimos anos destaca-se a construtivista, ao qual salienta a necessidade de assegurar um ambiente escolar cujas propostas didáticas levem os alunos a expor, reconhecer e refletir sobre as suas próprias ideias, expressando suas opiniões e aceitar que outras pessoas também a expressem, além de discutir e refletir a pertinência destas para a situação (JÓFILI, 2002). A esta proposta dois conceitos se sobrepõe, sendo o racionalista e o empirista, a estes Carvalho destaca:

1) o aluno é o construtor do seu próprio conhecimento;

2) o conhecimento é um contínuo, isto é, todo conhecimento é construído a partir do que já se conhecimento:

3) o conhecimento a ser ensinado deve partir do conhecimento que o aluno já traz para a sala de aula (CARVALHO, 1992, p.9).

Ou seja, essa corrente considera que a inteligência humana se desenvolve por meio de interações entre o indivíduo e o meio, de modo que o conhecimento passa por 
processos de assimilações e acomodações, construções e reconstruções, até que de fato seja compreendido pelo indivíduo.

Segundo Ausubel (1980) para que a aprendizagem seja de fato significativa para o aluno faz-se necessário partir daquilo que este já sabe, para isso preconiza que os educadores devam criar situações didáticas na qual os alunos possam expor os conhecimentos prévios existentes sobre determinado assunto ou conceito, assim aprender significativamente implica atribuir significados, aquilo que já é conhecimento, ou melhor:

[...] a aprendizagem significativa se caracteriza pela interação entre conhecimentos prévios e conhecimentos novos, e que essa interação é nãoliteral e não-arbitrária. Nesse processo, os novos conhecimentos adquirem significado para o sujeito e os conhecimentos prévios adquirem novos significados ou maior estabilidade cognitiva (MOREIRA, 2012, p.12).

Assim, "o aprender na escola precisa acontecer de forma significativa, dessa maneira a apropriação do conhecimento não pode partir do nada, mas sim, do conhecimento prévio, dos interesses e das experiências dos alunos (DAHER, 2017, p.4), de modo que tenha relação com seu cotidiano, caso isso não aconteça, a aprendizagem não passará de simples memorização, onde o aluno reproduzirá informações, leis e teorias transmitidas pelo professor.

Segundo Silva e Núñez (2007) as concepções alternativas, pré-concepções ou ainda conhecimentos prévios trazidos pelos estudantes são por vezes incoerentes com o conhecimento científico, pois estes são elaborações fruto de suas experiências cotidianas das quais estão dotadas de esquemas mentais, eficazes do ponto de vista cotidiano, mas algumas vezes ineficazes do ponto de vista científico.

Muitas vezes estes erros conceituais, estarão por servir de base para a compreensão de leis, teorias, e a resolução de problemas. Por isso, faz-se necessário criar situações que levem os alunos a exporem suas ideias frente aos conceitos físicos, para que não venham a construir conceitos e concepções errôneas sobre a ciência.

Assim, ao se perguntar como trabalhar os conteúdos de física em sala de aula, várias estratégias ganham evidência entre elas a utilização de questionários abertos, entrevistas e portfólios, ao qual se reportam como uma importante ferramenta para se compreender as concepções prévias dos estudantes e suas dificuldades de aprendizagem, como também a utilização de mapas conceituais que por meio de 
Edição Especial: I SSAPEC - Simpósio Sul-Americano de Pesquisa em Ensino de Ciências

ISSN: 2595- $4520 \quad$ Vol. 4, n. 3. 2021

diagramas hierárquicos buscam refletir a organização conceitual e as relações entre eles (MOREIRA, 1980).

Os Parâmetros Curriculares Nacionais para o Ensino Médio-PCNEM+(BRASIL, 2006), orientam situações de aprendizagem que exponham os alunos a problemas que de fato exijam a construção de modelos na análise das situações físicas, como estratégias estão a metodologia por projetos, as práticas de laboratório, problemas de lápis e papel como questões abertas e problemas abertos, demonstrações investigativas e laboratórios abertos (AZEVEDO, 2009), cujo “objetivo é levar os alunos a pensar, debater, justificar suas ideias e aplicar seus conhecimentos em situações novas, usando os conhecimentos teóricos e matemáticos" (AZEVEDO, 2009, p.20).

As resoluções de problemas deste tipo são importantes instrumentos para o desenvolvimento de habilidade e competências, como: organização, reflexão, raciocínio, argumentação, ação, entre outros, esse processo também auxilia na construção da autonomia do aluno, além disso, "os problemas sem dados no enunciado [...] obrigam os alunos a fazer hipóteses, a imaginar quais devem ser os parâmetros pertinentes e de que forma intervêm” (GIL PÉREZ, et al, 1992, p.15).

\subsection{Relação entre a Matemática e Física}

Sobre o ensino da física "ressalta-se a importância de um enfoque conceitual para além de uma equação matemática, sob o pressuposto teórico de que o conhecimento científico é uma construção humana com significado histórico e social"(PARANÁ, 2008, p.50). Nesta proposta, os modelos matemáticos tão necessários para a física não são deixados de lado, mas sim evocados gradativamente à medida que são requisitados para a solução de um problema, vistos como instrumentos auxiliadores a assimilação de conceitos novos.

Muito além da hierarquia dos sinais e equações matemáticas, dos erros e acertos, estão os procedimentos e atitudes que o estudante evoca ao tentar resolver um problema, para Azevedo (2009, p.21) estes “[...] se torna, dentro do processo de aprendizagem, tão importante quanto à aprendizagem de conceitos e/ou conteúdos”. A este sentido Lopes (2004, p.335), considera que:

A relação entre a Física e a Matemática deve ser progressiva, isto é, a exploração física das situações deve ser feita até que ela seja completamente compreendida. Logo que esse passo esteja assegurado, a situação física que 
Edição Especial: I SSAPEC - Simpósio Sul-Americano de Pesquisa em Ensino de Ciências

se está a estudar deve ser aperfeiçoada e precisada com a introdução progressiva da linguagem matemática [...] (LOPES, 2004, p.335).

$\mathrm{Na}$ introdução da linguagem matemática, e ao resolver problemas torna-se essencial a verbalização das ações, do reconhecimento de variáveis, da porque e qual equação utilizar, dos procedimentos matemáticos, de revisitar conceitos, e operações básicas quando necessário, de modo que a qualidade do ensino está na qualidade de sua comunicação, neste sentido deve-se evitar ao máximo operativismos carentes de significação física (BINI, 2005 e GIL PÉREZ et al, 1992).

Deste modo, a função do professor é, através das metodologias, provocar desequilíbrios que em termos corriqueiros significa "fazer desafios" (LIMA, 1980). Além disso, o professor construtivista deve ter a capacidade de perceber e aceitar as limitações de cada aluno; mostrar-se confiante; conhecer a matéria que ensina; fomentar debates em sala de aula; fazer perguntas "inteligentes"; e formular hipóteses sistematizando o conteúdo, quando necessário (SANTOS 2007).

\section{PROCEDIMENTOS DE PESQUISA}

O presente trabalho caracteriza-se como uma abordagem qualitativa, delimitado por uma revisão documental ou também conhecido como estado da arte, ao qual tem como um de seus objetivos mapear e investigar pesquisas voltadas, especialmente, para o ensino e aprendizagem da física térmica (Termodinâmica), a fim de identificar quais as $\operatorname{metodologias}$ e estratégias são utilizados por professores para o ensino e aprendizagem da Física a nível médio e como objetivo secundário propor uma sequência de ensino que contemple abordagens instigativas e problematizadoras para este ensino.

\subsection{Procedimentos de Coleta do Material investigado}

Para responder ao primeiro objetivo deste trabalho realizamos um levantamento sistemático em periódicos nacionais da área de Ensino de Física e Ensino de Ciências classificados como A1 e A2 no novo Qualis da Coordenação de Aperfeiçoamento de Pessoal de Nível Superior (CAPES). Além dos periódicos realizamos uma busca em dois importantes eventos em Ensino Ciências e Ensino de Física, sendo o Simpósio Nacional de Ensino de Física (SNEF) e Encontro Nacional de Pesquisas em Ensino de Ciências (ENPEC) com publicações bianuais. 
Foram mapeados em ambos os canais de divulgação - portal capes e site dos eventos - trabalhos no período de dez anos (2010-2020), no entanto, devido o caráter bianual dos eventos, essa busca se manteve entre 2011 e $2019^{1}$. Para a seleção dos periódicos utilizamos como base o instrumento propostos por Assai, Arrigo e Broietti (2018), porém de forma adaptada para nosso trabalho, sendo:

a) seleção dos periódicos a partir da classificação da última atualização da CAPES;

b) exclusão daqueles relacionados a área da matemática, biologia, ou química e também dos que não apresentam pesquisas da área de Ensino de Ciências e Ensino de Física;

c) opção pelos periódicos nacionais;

d) a utilização dos filtros "Física", "ensino", "ciência" e "educação".

Para a busca utilizamos a palavra "ensino" presente no título, ao qual culminou em um universo de 44 periódicos, em seguida utilizamos um outro filtro selecionando a área de conhecimento "multidiciplinar" (165 periódicos) e em seguida "ensino" obtendo 16 periódicos. Mudando o filtro do título de busca para "Física", encontramos 4 periódicos, "Ciência"- dezesseis (16) periódicos, e "Educação" vinte e um (21) periódicos. Após estes resultados realizamos um processo de análise e similaridade entre os quatros filtros estabelecidos (ensino, Física, educação e ciências), desta obtivemos 11 periódicos. Por fim foi verificado o qualis de cada revista com base no novo qualis da $\mathrm{Capes}^{2}$, resultando em 6 periódicos.

Para a seleção dos trabalhos utilizamos os descritores "termodinâmica", "calor", "temperatura", e "termologia" por meio da busca avançada dos descritores nos títulos e resumos. Para os periódicos e eventos que não possuíam ferramenta de busca realizamos buscas manuais dos trabalhos que continham os termos no título e/ou nas palavras-chave e, se ainda necessário era analisado o resumo do mesmo por meio de uma leitura flutuante

A partir dos critérios estabelecidos foram identificados 14 trabalhos em periódicos e 33 trabalhos em eventos. Posteriormente, realizou-se uma leitura minusciosa nos resumos dos trabalhos e em alguns casos na íntegra a fim de obter mais informações sobre a natureza do mesmo em relação ao nosso objetivo. Desta análise

\footnotetext{
${ }^{1}$ Não foi possível acessar as atas do XIX e XXIII SNEF pois não foi localizado no site do referido evento o campo atas ou anais para a obtenção dos trabalhos.

${ }^{2}$ https://files.cercomp.ufg.br/weby/up/102/o/Qualis_novos.pdf 
Edição Especial: I SSAPEC - Simpósio Sul-Americano de Pesquisa em Ensino de Ciências

ISSN: 2595- $4520 \quad$ Vol. 4, n. 3. 2021

alguns trabalhos foram descartados por se tratarem de propostas sem aplicações realizadas no ensino, ou por se tratar de aplicações em nível superior. Esta leitura resultou em 21 trabalhos, sendo 14 em eventos e 8 em periódicos, dos quais comporam o corpus deste trabalho.

\subsubsection{Procedimentos de Análise dos dados}

Para sintetizar e analisar as informações coletadas optamos por utilizar o próprio nome dos autores nos excertos retirados dos trabalhos, conforme o quadro abaixo, entretanto, para melhor identificação mantemos os nomes dos autores, o ano e a página com letras minúsculas e em negrito.

Quadro 1- Informações referente aos trabalhos analisados

\begin{tabular}{|l|l|l|l|}
\hline \multicolumn{1}{|c|}{ Autores } & \multicolumn{1}{|c|}{ Ano } & \multicolumn{1}{c|}{ Autores } & \multicolumn{1}{c|}{ Ano } \\
\hline (Moro; Neide;Rehfeldt, 2016) & CBEF & (Martins; Pereira, 2019) & XII ENPEC \\
\hline (Silva; Duarte, 2014) & CBEF & $\begin{array}{l}\text { Polonine;Silva; Ferracioli; } \\
2013\end{array}$ & XX SNEF \\
\hline (Reis, et al, 2018) & RBEF & (Soares; Schmiedecke, 2013) & XX SNEF \\
\hline (Passoni, et al, 2010) & RBECT & (Pastorio; Sauerwein, 2013) & XX SNEF \\
\hline (Santos;Nicot; Marques, 2020) & REnCiMa & (Silva, Rodrigues, 2013) & XX SNEF \\
\hline (Pereira, et al, 2020) O) 2) & REnCiMa & (Ambrózio; Coelho, 2013) & XX SENEF \\
\hline (Santos, et al, 2020) & REnCiMa & (Schiavon, et al, 2015) & XXI SNEF \\
\hline Carmo; Carvalho, 2012) & IEC & (Rodes, et al, 2017) & XXII SNEF \\
\hline $\begin{array}{l}\text { (Carvalho; Moreira; Aguiar } \\
\text { Júnior, 2015) }\end{array}$ & X ENPEC & (Souza, et al, 2017) & XXII SNEF \\
\hline (Ambrózio, Coelho, 2015) & X ENPEC & (Neres; Vanjura; Lima;2017) & XXII SNEF \\
\hline (Pedroso, et al, 2017) & $\begin{array}{l}\text { XI } \\
\text { ENPEC }\end{array}$ & $\begin{array}{l}\text { (Pereira; Campos; Silva, } \\
\text { 2017) }\end{array}$ & XI ENPEC \\
\hline
\end{tabular}

Fonte: elaborada pelos autores

Para a análise dos dados utilizou-se a análise de conteúdo de Bardin (2011). Escolhemos esta metodologia por se configurar dentre as diversas técnicas a que melhor

\footnotetext{
${ }^{3}$ Para a análise da Revista Brasileira em Ensino de Físca, optamos por analisar a Revista a Física na Escola por estar voltada a práticas no ensino básico. 
se adequa a nossa pesquisa, apresentando uma técnica de categorias que potencializa a sistematização, seleção e interpretação dos resultados. Neste trabalho optamos pela construção de categorias a posteriori, elaboradas a partir da leitura do corpus, sendo: CF - Conceitos da Termodinâmica; JE-Justificativas para a escolha; RTM Referenciais Teóricos/Metodológicos; EST - Estratégias; e AB - Avaliação da Abordagem. No próximo ítem apresentam-se detalhes da análise dos excertos com base em cada categoria.

\section{RESULTADOS}

Os conceitos de energia e as leis da Termodinâmica são tido pelos professores e pesquisadores da área de ensino de Física “como um tópico "impopular" entre os estudantes e difícil de se trabalhar, por tratar fenômenos em que a matemática que os exprime aparece dissociada do cotidiano vivenciado por esses indivíduos"(COLOVAN; SILVA, 2005, p.8).

Neste contexto ainda, outro fator de impacto está relacionado ao conceito base da Termodinâmica, como calor e temperatura. Os autores Schiavon, et al comentam que o conceito espontâneo de calor associado a sensação térmica entra em conflito com o conceito científico, no qual prevalece devido as suas experiências. Logo, “[... a contradição entre dois conceitos só pode ser percebida quando estes estão subordinados a conceitos mais gerais [...]" por isso a experimentação se torna tão importante , “[...] à medida que desenvolvemos essa prática para, partindo de situações ligadas ao uso concreto de objetos físicos, construirmos a diferenciação e conscientização desses dois tipos de conceitos" (Schiavon, et al, 2015, p.2).

No entanto segundo Souza (et al, 2017) oque se percebe sobre o estudo da calorimetria no ensino médio é a apresentação na maioria das vezes de forma expositiva, com pouco ou nenhuma abordagem experimental, por isso é tão comum as práticas de memorização. Neste sentido Neres, Vanjura e Lima (2017), na tentativa de contornar a reprodução de conteúdos e o foco a abordagem matemática apresentam uma outro olhar para a abordagem dos conceitos da dilatação térmica,

“[...]Como os alunos demonstravam pouca habilidade com as operações básicas de matemática, a estratégia utilizada foi a observação de estruturas físicas que permitiam a visualização de juntas de dilatação muito presentes na construção civil [...] (NERES, VANJURA, LIMA, 2017, p.1). 
Com base nestas ideias, os trabalhos investigados buscaram desenvolver estratégias diferenciadas a fim de tornar o estudo da termodinâmica para atrativo, dentre os cocneitos estão: condutores e isolantes (1), processos de propagação (4), dilatação(2), calor específico (1), escalas termométricas (1), temperatura (2), calor (2), equilíbrio térmico (1), estudo dos gases (1), estrutura da matéria (1), $1^{\circ}$ Lei da Termodinâmica (1), $2^{\circ}$ Lei da termodinâmica (1), maquinas térmicas (2).

Para a abordagem dos conceitos Passoni, et al (2010) salientam a importância do diálogo entre educador-educando (FREIRE, 1987; MOREIRA, 2010), de modo que "não existe a ação da construção do novo conhecimento a ser adquirido sem que ocorra a discussão e ordenação deste" (FREIRE, 1987, apud Passoni, et al 2010, p.34).

Neste sentido os autores Carmo e Carvalho mencionam a importância da linguagem em sala, destacando uso da linguagem oral, da escrita, das representações visuais e da matemática (Carmo; Carvalho, 2012). Martins e Pereira salientam a importância dos conteúdos conceituais, visando "[...] a construção de significados pelo estudante em relação a fatos, objetos, e símbolos [...]" (Martins; Pereira, 2019, p.2)

Pereira et al (2020) e outros autores abordam a necessidade em se conhecer as concepções prévias dos estudantes, tão "importante para a construção do conhecimento [...] fruto de suas experiências cotidianas e vivências diversas (Pereira, et al 2020, p.107). Neste sentido encontram embasamento na Teoria da Aprendizagem Significativa de Ausebel, na teoria Histórico-Cultural de Vygotsky (Schiavon, 2015), e no ensino por Investigação ao qual "constitui uma oportunidade para os alunos construírem novas concepções a partir dos conhecimentos anteriores"(Martins, Pereira, 2019,p.3), pois segundo Ambrózio e Coelho,

[...] Os alunos deverão passar de forma autônoma por todas as etapas que envolvem o processo de resolução de problemas, entre eles o levantamento de hipóteses, discussão das estratégias para se chegar ao objetivo da investigação, após o teste da hipótese, quando houver um experimento ou simulação computacional envolvidos, deverão repensar e rever o entendimento sobre o fenômeno estudado, retomar o objetivo inicial e questionar se haveriam outros caminhos para obtenção solução (Ambrózio; Coelho, 2013, p.2)

Entre os referênciais adotados os autores Carvalho e Moreira buscam ensinar os conteúdos da termodinâmica, "discutindo as implicações sociais do uso intensivo do motor de combustão e do modelo de mobilidade urbana centrado no carro particular" 
implementando deste modo o movimento CTS ao currículo de Física (Carvalho, Moreira, 2015, p.2), são destacados e discutidos ainda no referencial teórico o papel das TDIC no ensino e como método avaliativo, os jogos como recursos para a aprendizagem e a abordagem de mapas conceituais.

Concomitante a estas ideias destacam as estratégias utilizadas para a abordagem dos conceitos das quais vão desde o ensino por meio de problematizações (2), simulações computacionais (5), experimentos (6), mapas conceituais (1), textos paradidáticos (2), animações (1), peça teatral (1), ensino por projeto (1), jogos (2), além de questionários (2), testes (3) e o recurso plickers (1) como ferramenta para avaliação das concepções antes e após as abordagens.

Com base nas conclusões dos autores e a avaliação de suas abordagens pode-se constatar aspectos positivos e aspectos negativos como índicios de que algo precisa ser melhorado. Os autores Ambrózio e Coelho relatam que "o trabalho colaborativo, possibilitado pela distribuição dos estudantes em pequenos grupos, realmente fomentou as discussões e debates entre os seus componentes", outro fator positivo se manifesta “[...]na reação dos alunos diante da aceitação do erro durante a elaboração das soluções para os problemas”(Ambrózio; Coelho, 2015, p.8) . Silva e Duarte destacam ainda que:

"O posicionamento aberto dos alunos sobre pontos fortes vistos frente ao uso do material nos mostra que os pontos positivos destacados são: a questão da interatividade, o uso das animações, o vídeo, a praticidade de acesso aos conteúdos e a motivação despertada para as aulas de física" (Silva; Duarte, 2014, p.708)

Dentre outros destaca-se a potencialidade da proposta investigativa em tirar o aluno da posição passiva das aulas e colocá-los no centro do processo de aprendizagem, levando-o a "refletir, discutir, explicar fatos sobre as hipóteses envolvidas na solução de um problema, que pode ou não estar associado a um experimento e/ou simulação computacional" (Ambrózio;Coelho, 2015, p.2).

A capacidade de levar os estudantes a verificação de fenomênos que muitas vezes observam no cotidiano e a diferenciá-los no caso da transferência de energia (Moro; Neide; Rehfeldt, 2016, p.1004). A utilização do “jogo de tabuleiro auxiliou e motivou os alunos, facilitando a compreensão dos assuntos físicos e a minimização das dificuldades nas operações matemáticas, o que tornou a aula mais interativa e atraente culminando para a sua aprendizagem"(Reis, et al, 2018, p.61). 
Edição Especial: I SSAPEC - Simpósio Sul-Americano de Pesquisa em Ensino de Ciências ISSN: 2595- $4520 \quad$ Vol. 4, n. 3. 2021

Como um ponto de atenção os autores Pereira, et al citam que os questionaram apontaram a necessidade de aperfeiçoar a atividade (aquecedor solar) para que ela possa "melhor abordar a distinção e a relação entre os conceitos de calor e temperatura e os processos de transmissão de energia por calor"(Pereira, et al 2020, p.122).

No trabalho de Carvalho, Moreira e Aguiar Júnior o que precisa ser melhorado é a articulação entre as abordagens, pois a utilização da prblemática inicial e posteriormente a utilização do "livro didático como o principal recurso cria uma descontinuidade, que não explora todas as possibilidades da tecnologia do motor de combustão, em termos do desenvolvimento conceitual", este refletiu na motivação dos estudantes e na relação efetiva, tecnologia e conceitos (Carvalho; Moreira; Aguiar Júnior, 2015, p.7).

\section{DISCUSSÕES}

Com base nos resultados identificados anteriormente percebemos que existe entre os professores a visão defendida no referencial por Rosa e Rosa (2012) da qual revela a necessidade de se compreender a insuficiência do ensino tradicional e buscar novas ferramentas para se ensinar, cada qual em sua realidade buscou diferentes recursos para abordar os conceitos da Termodinâmica, dos quais despertaram a curiosidade o interesse, o engajamento e trabalho em grupo, a motivação, a reflexão e a aceitação dos erros.

No entanto, verificamos a partir dos excertos a necessidade do desenvolvimento de mais investigações sobre os conceitos básicos da Termodinânica como calor e temperatura, calor específico, capacidade térmica, e calor latente que não apareceu nos trabalhos investigados, sendo os primeiros a base para compreensão de toda a termodinâmica. Para guiar nossas discussões utilizaremos dois trabalhos que tiveram em suas abordagens o conceito de calor e estrutura da matéria, sendo o trabalho de Silva e Duarte (2014) e Polonine, Silva e Ferracioli (2013).

Silva e Duarte (2014) em seu trabalho, abordaram os conceitos básicos necessários à discussão da estrutura da matéria, tendo como objetido a diferenciação dos movimentos macroscópicos de um sólido e o movimento das partículas. O que buscamos evidenciar foram os aspectos das abordagens. Neste trabalho os autores o fizeram por meio de um material paradidático digital e interativo em formato pdf ao qual contava com o auxílio de animações e simulações, onde era possível o aluno ler e 
verificar através da imagem ou animação o movimento das moléculas no interior de um corpo. Antes e após a utilização do material os alunos eram submetidos a um questionário com questões abertas e de multipla escolha ao qual serviu de base para os autores verificarem a eficácia da proposta.

Compreendemos a proposta da atividade dos autores em relação ao potencial do material desenvolvido, no entanto, consideramos importante ao desenvolver estratégias de ensino oportunizar e fomentar o debate, exposição de ideias, e a exploração dos significados que os alunos tem para os conceitos, de modo que possam verbalizá-los e conflitá-los, a fim de verificar em alguns casos seus limites, mas que acima de tudo consiguam perceber a distinção dos conceitos.

Outro fator interessante é a utilização de questões de multipla escolha em questionários que visem detectar uma evolução nos conceitos dos estudantes, pois consideramos que as questões fechadas acabam por direcionar uma resposta pronta, e igual a todos, e sabemos que cada aluno desenvolve o conhecimento de uma forma e com base em suas experiências, ou melhor esquemas mais ou menos desenvolvidos.

O trabalho de Polonine, Silva e Ferracioli (2013).por sua vez traz uma abordagem para o conceito de calor com base em mapas conceituais. Nesta abordagem buscou-se a partir dos mapas, identificar os possíveis conceitos subsunçores referentes ao conceito de Calor, de modo a elaborar ações para mediar a construção do saber que o aluno precisa alcançar. Por meio da aplicação eles puderam identificar a confusão entre os conceitos de calor e temperatura expressos pelos alunos, bem como nas frases de ligação que não expressavam a adequada relação entre eles.

Estes mecanismos são muito interessante pois representam as hierarquias e estruturas que o conceito se estabelece no indivíduo. Logo, uma sugestão de abordagem é utilizá-los sempre antes e após a conclusão de um conteúdo, para que os alunos possam verificar o quanto aprenderam.

Para uma melhor análise das evoluções conceituais e das abordagens tanto a BNCC como os parâmetros orientam a necessidade de um sólido conhecimento conceitual pelo professor, acerca da linguagem e teorias da física, pois estas são a base para uma compreensão e avaliação mais profunda da ciência, além de, conhecimento de “conteúdos de Didática e Pedagogia, de modo a poder planejar e implementar propostas para o ensino de conhecimentos científicos"(CARVALHO; SASSERON, 2018, p.43- 
44), ou seja, para que as ferramentas perpassem a visão do lúdico o professor precisa conhecer de ante mão e ter bem delimitado a estrutura das aulas em momentos, os objetivos e a metodologia ao qual fundamentará a ação e potenciará o instrumento.

Outro fator de impacto e presente nas abordagens dos professores está relacionado ao erro do método, a insuficiência de uma ou outra abordagem. Precisamos ser conscientes que existem metodologias que melhor se adequa a um ou outro conteúdo, ou a turmas específicas, e que a compreensão e o engajamento dos alunos pode levar tempo, mas que "as constantes abordagens experimentais feitas em sala de aula também contribuem para esta "facilidade" no desenvolvimento de algumas atividades, com exposição crítica e investigativa dos fenômenos físicos"(MARTINS; PEREIRA 2019, p.9) confrome apotam os autores.

\section{CONSIDERAÇÕES FINAIS}

Deste modo, concluímos que a utilização de investigações no ensino por meio de, problemas abertos, experimentos, simuladores, animações, projetos temáticos e a bordagem CTSA, configuram-se como excelentes ferramentas na construção da aprendizagem, além de contribuir para o despertar da autonomia do estudante, levandoos a formular hipóteses, articular conceitos, e expressar suas ideias com os demais, ao invés de simplesmente reproduzir valores e equações sem ao menos compreender o que significa.

Logo, não somente as práticas precisam de atenção, é necessário que o conteúdo passe por adequações, bem como os problemas, vistos que não são do tipo proposto pelos livros didáticos, nem muito menos presentes em avaliações institucionais, precisam passar por uma modificação de forma que sua leitura permita explorar vários conceitos, por isso, chamados problemas investigativos, onde a sua resolução requer habilidades que não podem ser aprendidas com o outro, ou até mesmo memorizada, ou copiada de alguém.

Assim, com base nos dados e discussões apresentados acreditamos que com uma boa fundamentação metodológica, ancorada por estratégias diferenciadas, e guiada pelo estudo e reflexão de trabalhos científicos, poderemos melhorar o ensino de física a nível médio, despertando no estudante a curiosidade e a motivação em aprender. Esperamos que este trabalho possa contribuir para um ensino de física muito mais dinâmico e atrativo no ensino médio. 


\section{REFERÊNCIAS}

AUSUBEL, D. P.; NOVAK, J.; HANESIAN, H.. Psicologia Educacional, Rio de Janeiro: Interamericana, 1980.

ANTONOWISKI, R.; ALENCAR, M. V.; ROCHA, L. C. T. Dificuldades encontradas para aprender e ensinar física moderna. Sci. Elec. Arch. Vol. 10 (4), 2017.

ASSAI N. D. S.; ARRIGO, V.; BROIETTI, F. C. D.. Uma proposta de mapeamento em periódicos nacionais da área de ensino de ciências. Revista de Produtos Educacionais e Pesquisa em Ensino, 2(1), 150-166, 2018. Diaponível em: $\langle$ http://seer.uenp.edu.br/index.php/reppe/article/view/1380/675 $>$.

AZEVEDO, M. C. P. S. de.Ensino por Investigação: Problematizando as atividades em sala de aula. Org. Anna Maria Pessoa de Carvalho. Ensino de Ciências: Unindo a Pesquisa e a Prática. São Paulo: Cengage Learning, 2009.

BEZERRA, D.P; et al. A evolução do ensino da física - perspectiva docente. SCIENTIA PLENA, VOL. 5, NUM. 9, 2009

BRASIL. Orientações Curriculares para o Ensino Médio: Ciências da Natureza, Matemática e suas Tecnologias, v. 2, 135p. Brasília: Ministério da Educação,Secretaria de Educação Básica, 2006.

BRASIL. Ministério da Educação (MEC). Secretaria de Educação Média e Tecnológica (Semtec). PCN + Ensino Médio: orientações complementares aos Parâmetros Curriculares Nacionais -Brasília, DF: MEC/Semtec, 2002. Disponível em:< http://www.sbfisica.org.br/arquivos/PCN_FIS.pdf>. Acesso em: 17 de jan. 2021

BINI, R.C. Como o cérebro aprende. Florianópolis: CEITEC. 2005.

BONADIMAN, H.; NONENMACHER, S. E. B.. O gostar e o aprender no ensino de física: uma proposta metodológica. Cad. Bras. Ens. Fís., v. 24, n. 2: p. 194-223, ago. 2007.

CARVAlHO, A. M. P. de. Construção do conhecimento e ensino de Ciências. Em Aberto, Brasília, ano 11, nº 55, jul./set. 1992

CARVALHO, A. M. P. Ensino de física. São Paulo: Gengage Learning, 2011. v. 1

CARVALHO, A.M P. de; SASSERON, L. H. Ensino e aprendizagem de Física no Ensino Médio e a formação de professores. Estudos Avançados 32 (94), 2018

COLOVAN, S. C. T.; SILVA, D. A Entropia no Ensino Médio: Utilizando Concepções Prévias dos Estudantes e Aspectos da Evolução do Conceito. Ciência \& Educação, v. 11, n. 1, p. 98-117, 2005.

CLEMENT, L.; TERRAZZAN, E. A.; Resolução de problemas de lápis e papel numa abordagem investigativa. Experiências em Ensino de Ciências,v.7, n.. 2, 2012.

Aceito em: 24/02/2021 
DAHER, A. F. B. Aluno e professor: protagonistas do processo de aprendizagem. 2017 Disponível em:< http://www.campogrande.ms.gov.br/semed/wpcontent/uploads/sites/5/2017/03/817alunoeprofessor.pdf $>$. Acesso em: 18 de jan/ 2021

FRIGO, F.; SEHN, E. Propostas metodológicas para motivar o processo ensino aprendizagem da física. Revista Eletrônica Científica Inovação e Tecnologia, Medianeira, v. 8, n .15, 2017.

GIL PEREZ, D.; MARTINEZ TORREGROSA, J.; RAMIREZ, L.; DUMASCARRÉ, A.; GOFARD, M.; CARVALHO, A.M.P. Questionando a didática de resolução de problemas: elaboração de um modelo alternativo. Caderno Catarinense de Ensino de Física, 9 (1): 7-19, 1992.

GIL PÉREZ, D.; MARTÍNEZ TORREGROSA, J.; SENENT PÉREZ, F.: ‘El fracaso em la resolucion de problemas de física: uma investigación orientada por nuevos supuestos.' In: Enseñanza de las Ciências, Barcelona/Valencia/ESP: UAB/UV, v.6 n.2, 1988 .

JÓFILI, Z. Piaget, Vygotsky, Freire e a construção do conhecimento na escola. In:Educação: Teorias e Práticas, Ano 2, n.2 dez.2002.

LIMA, L. de O.. Piaget para principiantes. São Paulo: Summus, 1980.

LOPES, B. J. Aprender e Ensinar Física. Fundação Calouste Gulbenkian . 2004.

MARTINS, A. F. P. Natureza da Ciências no Ensino de Ciências: uma proposta baseada em "temas" e "questões". Cad. Bras. de Ens. de Fís., v. 32, n. 3, p. 703-737, dez. 2015.

MOREIRA, M. A. Grandes desafios para o ensino da física na educação contemporânea. Revista do Professor de Física, vol. 1, n. 1, 2017. Disponível em:< https://periodicos.unb.br/index.php/rpf/article/view/7074>. Acesso em:02/10/2020

MOREIRA, M. A. O que é afinal aprendizagem significativa? Qurriculum, La Laguna, Espanha, 2012.

MOREIRA, M. A. Mapas conceituais como instrumentos para promover a diferenciação conceitual progressiva e a reconciliação integrativa. Ciência e Cultura, 32(4), p.474-479, 1980

MENEGOTTO, J.C.; ROCHA FILHO, J. B da. Atitudes de estudantes do ensino médio em relação à disciplina de Física. Revista Electrónica de Enseñanza de las Ciencias, Vol. 7 n², 2008.

PARANÁ. Secretaria de Estado da Educação. Diretrizes Curriculares dda Educação Básica:Física. Curitiba: SEED, 2008. 
Edição Especial: I SSAPEC - Simpósio Sul-Americano de Pesquisa em Ensino de Ciências

ROSA C. W. da; ROSA, A. B. da. O ensino de ciências (Física) no Brasil: da história às novas orientações educacionais. Revista Iberoamericana de Educação, $n^{\circ} 58 / 2$, p. 1 24 , fevereiro/2012.

SANTOS, F. M dos. Significações de Construtivismo na perspectiva de professores "construtivistas" e sua relação com práticas avaliativas. 2007. 136 f. Dissertação (Mestrado em Educação) - Universidade Católica de Brasília, 2007.

SILVA, M. G. L.; NÚÑEZ, I. B. Concepções alternativas dos estudantes. Natal: SEDIS/ UFRN, 2007. 